\title{
Desenvolvimento de Helicoverpa spp. em milho Bt com expressão de diferentes proteínas
}

\author{
Christiane Almeida dos Santos(1), Rosangela Cristina Marucci(2), Tatiane Aparecida Nascimento Barbosa(1), \\ Octavio Gabryel Araujo(1), José Magid Waquil( ${ }^{(3)}$, Aline Silvia Dias ${ }^{(1)}$, \\ Fabrício Carvalho Hebach(1) e Simone Martins Mendes ${ }^{(1)}$
}

\begin{abstract}
(1)Embrapa Milho e Sorgo, Rodovia MG 424, Km 45, Caixa Postal 231, CEP 35701-970 Sete Lagoas, MG, Brasil. E-mail: chris.as.p@hotmail.com, taty71@hotmail.com, octavio_gabriel1991@hotmail.com, alinedias518@gmail.com, fabricioufsj@outlook.com, simone.mendes@embrapa.br (2)Universidade Federal de Lavras, Departamento de Entomologia, Caixa Postal 3037, CEP 37200-000 Lavras, MG, Brasil. E-mail: rosangelac.marucci@den.ufla.br ${ }^{\left({ }^{3}\right)}$ Consultor em Manejo Integrado de Pragas, Rua Jovelino Lanza, no 210, CEP $35700-353$ Sete Lagoas, MG, Brasil. E-mail: jmwaquil@gmail.com
\end{abstract}

Resumo - O objetivo deste trabalho foi avaliar os aspectos biológicos de Helicoverpa zea e Helicoverpa armigera (Lepidoptera: Noctuidae) em híbridos de milho com expressão de diferentes proteínas. Foram avaliadas as proteínas Cry1F, Cry1A(b), Cry1A.105 + Cry2Ab2 e Vip3A e seus respectivos isogênicos convencionais. As larvas foram alimentadas com espiguetas de milho Bt e convencional, trocadas a cada dois dias. Os parâmetros avaliados foram: sobrevivência 48 horas após eclosão, sobrevivência larval, peso de larvas e de pupas, período de desenvolvimento larval e período pré-imaginal. Observou-se efeito significativo da interação entre evento de milho Bt e espécie de Helicoverpa para todas as variáveis biológicas avaliadas. Larvas de $H$. armigera apresentaram maior sobrevivência 48 horas após eclosão em milho expressando a proteína Cry1F e a Vip3 em relação a H. zea. O período letal foi maior em H. armigera do que em H. zea, mas, em milho com expressão da proteína Cry1A(b), foi quatro vezes menor. Não houve sobrevivente para ambas as espécies de Helicoverpa em nenhum dos híbridos Bt avaliados. Nos isogênicos convencionais, o índice de adaptação de $H$. armigera foi superior ao de $H$. zea, o que indica maior facilidade de adaptação ao ambiente dessa espécie.

Termos para indexação: biotecnologia, manejo de resistência de insetos, manejo integrado de pragas, Noctuidae, proteínas Bt.

\section{Development of Helicoverpa spp. in Bt maize expressing different proteins}

Abstract - The objective of this work was to evaluate the biological responses of Helicoverpa zea and Helicoverpa armigera (Lepidoptera: Noctuidae) in maize hybrids expressing different proteins. The Cry1F, Cry1A(b), Cry1A.105 + Cry2Ab2, and Vip3A proteins and their isogenic conventional counterparts were evaluated. Larvae were fed on spikelets of $\mathrm{Bt}$ and conventional maize, which were changed every two days. The variables evaluated were: survival 48 hours after hatching, larval survival, larval and pupal weight, larval development period, and pre-imaginal period. There was a significant interaction between Bt maize event and Helicoverpa species for all evaluated biological variables. Helicoverpa armigera larvae showed higher survival 48 hours after hatching on maize expressing the Cry1F and Vip3 proteins when compared to H. zea. Lethal period was greater for $H$. armigera than for $H$. zea, but, in maize expressing Cry $1 \mathrm{~A}(\mathrm{~b})$ protein, it was four times lower. There were no survivals for both Helicoverpa species in the evaluated Bt hybrids. In isogenic conventional counterparts, the adaptation index of $H$. armigera was higher than that of $H$. zea, which indicates greater ease of adaptation to the environment of that species.

Index terms: biotechnology, insect resistance management, integrated pest management, Noctuidae, Bt proteins.

\section{Introdução}

A produção de milho (Zea mays) no Brasil aumenta a cada safra, o País ocupa o terceiro lugar no ranking mundial, atrás apenas da China e EUA (United States Department of Agriculture, 2015). Estima-se que a produção em 2014 tenha alcançado cerca de 80 milhões de toneladas (Acompanhamento..., 2014). Entre os fatores que contribuíram para o aumento da produção desse cereal destaca-se o emprego da transformação genética de plantas visando ao controle de pragas (Michelotto et al., 2011; Waquil et al., 2013). 
Organismos geneticamente modificados (OGMs), como as plantas $\mathrm{Bt}$ que contêm genes da bactéria Bacillus thuringiensis, controlam insetos por produzirem proteínas codificadas pelo gene cry, que, após ingeridas, causam danos no intestino médio dos insetos (Bravo et al., 2007; Carneiro et al., 2009; Michelotto et al., 2011). O plantio de culturas Bt no Brasil tem se intensificado, com destaque para o milho GM, cuja área plantada, na safra 2014/2015, foi de 12,5 milhões de hectares, representando $83 \%$ da área total (Informativo Céleres, 2015).

Uma das principais pragas da cultura do milho é a lagarta-da-espiga, Helicoverpa zea (Boddie, 1850) (Lepidoptera: Noctuidae), de grande importância econômica para a agricultura mundial. Relatada no Brasil com incidência de quase $97 \%$ de infestações em espigas de milho, além dos danos causados diretamente nos grãos em formação, essa praga interfere no desenvolvimento de uma segunda espiga, ou impede a fertilização de grande parte dos óvulos, e causa falhas na formação dos grãos da extremidade livre das espigas (Cruz, 2008). Além dos danos físicos e fisiológicos nas estruturas reprodutivas da planta de milho, os orifícios deixados pela larva na espiga propiciam a entrada de patógenos, principalmente fungos que produzem micotoxinas (Boiça Jr. et al., 2001; Garcia et al., 2006).

$\mathrm{Na}$ safra agrícola 2012/2013, registrou-se a ocorrência da espécie Helicoverpa armigera (Hubner, 1805) (Lepidoptera: Noctuidae) em lavouras de soja e algodão no Brasil (Czepak et al., 2013; Specht et al., 2013). A ocorrência desse inseto-praga, em níveis que causam danos às lavouras, em muitos casos está ligada a práticas inadequadas de manejo adotadas pelos produtores, por exemplo, o uso excessivo de inseticidas, ou a exploração de duas ou três safras em uma mesma área de lavouras com plantas hospedeiras, o que favorece espécies polífagas formando o que se denomina de ponte-verde. Helicoverpa armigera é uma das principais pragas de hábito polífago, caracterizada por se alimentar tanto nas estruturas reprodutivas como nas vegetativas das plantas (Cunningham \& Zalucki, 2014). Essa espécie tem sido registrada como praga de importância econômica em 181 espécies de plantas cultivadas em 45 famílias (Srivastava et al., 2010). Esse fato pode ser atribuído à alta fertilidade, comportamento migratório, adaptabilidade a diversas condições climáticas e seleção para resistência a ampla gama de inseticidas (Naseri et al., 2010). A ocorrência desse inseto-praga, em muitos casos, também pode estar relacionada a práticas inadequadas adotadas pelos produtores, como, por exemplo, o uso excessivo de inseticidas, ou a exploração de duas ou três safras em uma mesma área de lavouras com plantas hospedeiras.

Por se tratar de uma espécie recente no País (Czepak et al., 2013), estudos bioecológicos com hospedeiros presentes nas condições tropicais são necessários, pois representa um risco à agricultura brasileira. Além disso, o comportamento de $H$. zea e H. armigera ante as proteínas $\mathrm{Bt}$ expressas em milhos cultivados no País é fundamental para aportar estratégias de manejo integrado e manejo de resistência, no sistema produtivo vigente.

O objetivo deste trabalho foi avaliar os aspectos biológicos de Helicoverpa zea e $H$. armigera em híbridos de milho com expressão de proteínas Cry1F, Cry1A(b), Cry1A.105 + Cry2Ab2 e Vip3A e seus respectivos isogênicos convencionais.

\section{Material e Métodos}

O experimento foi conduzido no Laboratório de Ecotoxicologia e Manejo de Insetos da Embrapa Milho e Sorgo, em Sete Lagoas, MG, no segundo semestre de 2013 e primeiro semestre de 2014.

Os híbridos de milho utilizados foram: $30 \mathrm{~F} 35 \mathrm{YG}$ (MON 810 - Monsanto, Cry1A(b)); 30F35HX (Herculex - Dow Agroscience, Cry1F); Impacto Viptera (Viptera - Syngenta, Vip3A); e DKB390 VTPRO (MON 89034 - Monsanto Cry1A.105 + Cry2Ab2). Como tratamento controle utilizaram-se os respectivos isogênicos convencionais de cada híbrido: 30F35, Impacto e DKB 390. As plantas de milho foram cultivadas no campo experimental da Embrapa Milho

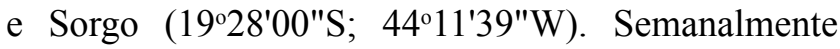
realizou-se o plantio, em linhas de 15 metros para cada híbrido. Utilizaram-se espigas não polinizadas no estádio de minimilho, que expressam a proteína $\mathrm{Bt}$ como a planta mãe, ou seja, o esporófito não segregante. As espigas em formação foram mantidas isoladas com sacos de plástico $(20 \times 10 \mathrm{~cm})$ para evitar qualquer tipo de polinização, tendo sido colhidas quando as plantas apresentavam o estádio VT (antes do R1).

Os bioensaios foram realizados no laboratório, com fotofase de 12 horas, temperatura de $26 \pm 2^{\circ} \mathrm{C}$ e UR de $60 \pm 10 \%$. As larvas das duas espécies foram obtidas da criação mantida em laboratório, sendo $H$. zea 
proveniente de coletas em plantios de milho dos campos experimentais da Embrapa Milho e Sorgo em 2013, e H. armigera da lavoura de algodão do município Luiz Eduardo de Magalhães, BA (19²8'00"S; 44ํ1'39"W) em 2013.

O bioensaio com $H$. zea foi realizado com gerações $\mathrm{F} 1$ e F2 de laboratório e com $H$. armigera com as gerações F2 e F3. As larvas recém-eclodidas de cada espécie de Helicoverpa foram confinadas em recipientes de plástico de $50 \mathrm{~mL}$ (tipo coletor universal), contendo as espiguetas de milho (estádio VT) para cada tratamento avaliado.

As variáveis avaliadas foram: a) sobrevivência larval 48 horas após a eclosão - cinco lagartas recém-eclodidas foram confinadas em recipiente, o qual foi considerado uma repetição, tendo sido registrados o número de insetos vivos e de mortos 48 horas após a montagem do bioensaio; b) sobrevivência larval (\%) - depois da avaliação da sobrevivência de 48 horas, as larvas sobreviventes foram individualizadas no recipiente supracitado, para evitar o canibalismo, e avaliou-se a sobrevivência durante todo o período larval até a fase de pupa. Nessa fase, considerou-se uma repetição como um grupo de quatro insetos; c) período letal (dias) a cada 48 horas observou-se o desenvolvimento dos insetos, registrando-se o período letal para aquelas larvas que morreram antes de completar a fase de pupa; d) período de desenvolvimento larval (dias) - acompanhou-se o desenvolvimento das larvas, registrando-se o período que cada larva levou para chegar à fase de pupa; e) peso das larvas (mg) foi registrado 7 dias após a eclosão, utilizando-se balança analítica $(0,001 \mathrm{mg})$, modelo AB204, classe 1 (Mettler Toledo Ind. e Com. Ltda., Barueri, SP); f) sobrevivência pré-imaginal (\%) - calculada pelo número de insetos que sobreviveram até a fase adulta, sendo agrupados em quatro indivíduos para cada repetição; g) período de desenvolvimento pré-imaginal (dias) - período compreendido desde a eclosão das larvas até a emergência dos adultos; h) peso de pupas $(\mathrm{mg})$ - o peso das pupas foi registrado no primeiro dia após sua observação, utilizando-se balança de precisão $(0,001 \mathrm{mg})$. O número de repetições (n) para essas variáveis não foi fixo, em função da mortalidade dos insetos dentro de cada tratamento. Assim, cada valor de $\mathrm{n}$ está apresentado nas Tabelas 1 e 2 .

Calculou-se também o Índice de Adaptação (IA), de acordo com metodologia proposta por Boregas et al. (2013): $\mathrm{IA}=(\mathrm{SBL} \times \mathrm{PP}) /(\mathrm{PDL})$, em que SBL, sobrevivência larval; PP, peso de pupas; e PDL, período de desenvolvimento larval.

Utilizou-se o delineamento experimental inteiramente casualizado em esquema fatorial, considerando as duas espécies de Helicoverpa como um fator e o milho (Bt ou não) como outro fator. Os dados foram submetidos à análise de variância, e as médias foram comparadas pelo teste de Scott Knott, a 5\% de probabilidade, com auxílio do programa estatístico Sisvar 5.0 (Universidade Federal de Lavras, Lavras, MG). Os dados de percentual de sobrevivência larval e pré-imaginal foram transformados em $(\mathrm{x}+1)^{0,5}$.

\section{Resultados e Discussão}

O efeito da interação entre espécies de Helicoverpa e os híbridos de milho em relação ao percentual de sobrevivência 48 horas após a eclosão foi significativo (Tabela 1). Para os híbridos 30F35 (Cry1Ab) e DKB390, a porcentagem de sobrevivência para as duas espécies de Helicoverpa foi similar. De modo geral, para as larvas de $H$. armigera observou-se maior sobrevivência 48 horas após a eclosão, nos híbridos que expressavam as proteínas Cry1F e Vip3A, quando comparadas às larvas de $H$. zea. $\mathrm{O}$ mesmo ocorreu nos isogênicos convencionais 30F35 e Impacto para $H$. armigera, que apresentou maior sobrevivência inicial, quando comparada a $H$. zea.

Avilla et al. (2005) testaram o efeito da inibição de 11 proteínas Bt sobre larvas neonatas de $H$. armigera, e constataram maior atividade das proteínas Cry1Ac4 e Cry2Aa1, na concentração letal 50 de 3,5 e 6,3 $\mathrm{g} \mathrm{mL}^{-1}$, respectivamente. De acordo com os autores, isto evidenciou comportamento diferencial de cada proteína cry no desenvolvimento dessa espécie. Comportamento similar ocorreu no presente estudo, no qual a sobrevivência inicial dessa espécie foi diferenciada para os híbridos de milho que expressam diferentes proteínas do Bt. Isso indica possibilidade de ação diferenciada em condições de campo quando se utilizam distintos eventos Bt com foco em espécies de Helicoverpa. Essa ação específica para cada proteína Bt foi relatada por Waquil et al. (2002) para Spodoptera frugiperda (J. E. Smith, 1797) (Lepidoptera: Noctuidae) e deve estar vinculada a ações de manejo de resistência desses lepidópteros relacionados.

Verificou-se interação entre os híbridos de milho e as espécies de Helicoverpa quanto à sobrevivência da fase

Pesq. agropec. bras., Brasília, v.51, n.5, p.537-544, maio 2016 DOI: 10.1590/S0100-204X2016000500014 
larval, que foi próxima de zero para todos os eventos $\mathrm{Bt}$ avaliados. Apenas para larvas mantidas nos isogênicos convencionais houve diferença, com destaque para a espécie $H$. armigera, com maior porcentagem de sobreviventes que $H$. zea. A maior sobrevivência larval de $H$. armigera, quando comparada a $H$. zea, corrobora observações de Ávila et al. (2013) e Tay et al. (2013) em relação à grande habilidade dessa espécie de adaptação ao ambiente adverso.

Diferença entre a efetividade de proteínas Bt na sobrevivência de $H$. armigera também foi constatada por Babu et al. (2002), que avaliaram a toxicidade e inibição do crescimento em relação à alimentação dessa espécie com proteínas Cry1Ac e Cry2Aa, e verificaram menor sobrevivência em Cry1Ac. Também observaram alto percentual de inibição do crescimento na proteína Cry2Aa, apesar de as larvas apresentarem um percentual de praticamente $100 \%$ em concentração de proteína, de $0,5 \mu \mathrm{g} \mathrm{mL}^{-1}$. Li \& Bouwer (2012) avaliaram a toxicidade de várias proteínas $\mathrm{Bt}$ a $H$. armigera, e encontraram maior toxicidade para a proteína Cry $1 \mathrm{Ab}$ em relação às demais proteínas estudadas, entre elas Cry1F. Quando avaliada a toxicidade de Cry2Ab2, esta foi menos ativa para $H$. Armigera, e Vip3A foi a mais tóxica, corroborando dados encontrados no presente estudo, no qual a mortalidade larval foi maior em milho que expressa Cry1Ab, Cry1A.105 + Cry2Ab2 e Vip3A, em detrimento de Cry1F.

Foi detectada interação significativa entre as espécies de Helicoverpa e híbrido de milho para o período letal. Para milho Cry1F, as larvas de $H$. zea morreram 3,6 vezes mais rápido que larvas de $H$. armigera e, para Vip3A, 3,5 vezes mais rápido (Tabela 1). Em milho Cry1A(b), ocorreu o inverso para o período letal. As larvas de $H$. armigera morreram 3,8 vezes mais rápido que as larvas de $H$. zea, ou seja, houve redução de cerca de quatro vezes em relação ao período letal para $H$. zea. $O$ período letal foi similar nas duas espécies para o híbrido que expressa Cry1A.105 + Cry2Ab2. Esses dados são similares aos encontrados por Mendes et al. (2011), para $S$. frugiperda, em que larvas mantidas em milho que expressa Cry1 Ab apresentaram ciclo mais longo. No presente estudo, larvas de $H$. zea mantidas em milho expressando Cry $1 \mathrm{Ab}$ apresentaram maior período letal quando comparadas a $H$. armigera. Isso evidenciou interação entre a eficiência de diferentes proteínas $\mathrm{Bt}$ e as espécies de noctuídeos-praga que ocorrem no milho. Além disso, Waquil et al. (2013) encontraram ausência de dano em espigas de milho Cry1A.105 + Cry2Ab2, o que mostra que o pequeno período em que as lagartas sobrevivem pode não ser suficiente para causar danos nas espigas. Assim,

Tabela 1. Média \pm erro-padrão da sobrevivência após 48 horas (SOB48) e larval (SOBL), do período letal e do período de desenvolvimento larval (PDL) de Helicoverpa zea e Helicoverpa armigera em diferentes híbridos de milho Bt e seus respectivos isogênicos convencionais ${ }^{(1)}$.

\begin{tabular}{|c|c|c|c|c|c|}
\hline \multirow[t]{2}{*}{ Milho } & \multirow[t]{2}{*}{ Espécie } & \multicolumn{4}{|c|}{ Parâmetro biológico } \\
\hline & & SOB48 $(\%)$ & SOBL $(\%)^{(2)}$ & Período letal (dias) & PDL (dias) \\
\hline \multirow{2}{*}{ 30F35HX (Cry1F) } & H. zea & $56,4 \pm 0,25 b(n=72)$ & $1,0 \pm 0,96 \mathrm{a}(\mathrm{n}=26)$ & $8,1 \pm 0,50 b(n=70)$ & - \\
\hline & H. armigera & $90,0 \pm 0,47 a(n=60)$ & $4,54 \pm 0,32 \mathrm{a}(\mathrm{n}=11)$ & $15,0 \pm 0,93 a(n=41)$ & - \\
\hline \multirow{2}{*}{ 30F35YG (Cry1A(b)) } & H. zea & $26,4 \pm 0,33 a(n=72)$ & $0,92 \pm 0,91 \mathrm{a}(\mathrm{n}=27)$ & $14,8 \pm 0,86 a(n=46)$ & - \\
\hline & H. armigera & $19,2 \pm 0,29 a(n=48)$ & $0,00 \mathrm{a}(\mathrm{n}=11)$ & $3,8 \pm 0,19 b(n=48)$ & - \\
\hline \multirow{2}{*}{$30 \mathrm{~F} 35$} & H. zea & $87,5 \pm 0,53 b(n=72)$ & $6,0 \pm 2,61 b(n=25)$ & $10,7 \pm 0,48 b(n=72)$ & $13,2 \pm 0,33 a(n=23)$ \\
\hline & H. armigera & $97,1 \pm 0,84 a(n=46)$ & $43,8 \pm 6,96 a(n=12)$ & $13,1 \pm 0,74 a(n=23)$ & $13,3 \pm 0,24 a(n=10)$ \\
\hline \multirow{2}{*}{ Impacto Viptera (Vip3a) } & H. zea & $1,9 \pm 0,67 b(n=72)$ & $0,00(n=25)$ & $2,3 \pm 0,09 b(n=96)$ & - \\
\hline & H. armigera & $44,0 \pm 0,27 \mathrm{a}(\mathrm{n}=74)$ & $0,00(\mathrm{n}=11)-$ & $4,0 \pm 0,15 \mathrm{a}(\mathrm{n}=47)$ & - \\
\hline \multirow{2}{*}{ Impacto } & H. zea & $85,0 \pm 0,51 b(n=72)$ & $8,7 \pm 3,37 b(n=23)$ & $10,9 \pm 0,48 \mathrm{a}(\mathrm{n}=72)$ & $15,1 \pm 0,69 a \mathrm{n}=10)$ \\
\hline & H. armigera & $95,9 \pm 0,75 a(n=48)$ & $62,5 \pm 9,48 \mathrm{a}(\mathrm{n}=12)$ & $12,3 \pm 1,12 \mathrm{a}(\mathrm{n}=17)$ & $13,9 \pm 0,27 b(n=30)$ \\
\hline \multirow{2}{*}{$\begin{array}{l}\text { DKB } 390 \text { VT PRO } \\
\text { (Cry1A.105+Cry2Ab2) }\end{array}$} & H. zea & $14,7 \pm 0,45 b(n=72)$ & $0,00(n=19)$ & $5,9 \pm 0,39 a(n=60)$ & - \\
\hline & H. armigera & $23,8 \pm 0,33 a(n=75)$ & $0,00(\mathrm{n}=9)$ & $5,1 \pm 0,26 \mathrm{a}(\mathrm{n}=36)$ & - \\
\hline \multirow{2}{*}{ DKB 390} & H. zea & $82,9 \pm 2,13 a(n=24)$ & $4,3 \pm 1,91 b(n=35)$ & $10,0 \pm 0,48 b(n=72)$ & $15,0 \pm 0,63 a(n=6)$ \\
\hline & H. armigera & $78,3 \pm 3,17 a(n=96)$ & $28,9 \pm 7,46 a(n=19)$ & $13,7 \pm 0,85 a(n=20)$ & $13,7 \pm 0,40 a(n=23)$ \\
\hline Coeficiente de variação (\%) & & 39,19 & 56,06 & 43,60 & 11,95 \\
\hline
\end{tabular}


as características de cada evento precisam ser consideradas em programas de manejo de pragas, pois a presença das larvas pode não significar ineficiência do evento, mas o efeito letal mais demorado.

Houve também interação entre espécie de Helicoverpa e híbrido de milho em relação ao período de desenvolvimento larval, e somente as larvas que se alimentaram de isogênicos convencionais completaram o desenvolvimento larval. Observou-se diferença para larvas mantidas no híbrido Impacto, com maior período de desenvolvimento larval para H. zea (Tabela 1). Farias et al. (2013) encontraram danos nas espigas de milho Cry1 Ab, contudo, com as espigas já polinizadas: podendo, portanto, expressar a proteína de forma alterada em virtude da segregação. Além disso, Balieiro Neto et al. (2013) encontraram menores níveis dessa proteína na espiga, o que pode justificar a maior mortalidade encontrada no presente estudo, no qual não foram utilizadas espigas com grãos formados.

Os dados da sobrevivência pré-imaginal acompanharam a tendência dos valores de sobrevivência larval, em que houve interação entre híbrido de milho e a espécie de Helicoverpa. Para todos os eventos Bt, não houve diferença significativa, e a sobrevivência foi próxima a zero. Uma maior taxa de sobrevivência de $H$. armigera, comparada a $H$. zea, foi encontrada para as larvas mantidas em espiguetas de milho do isogênico não Bt Impacto (Tabela 2). Vale ressaltar que no presente estudo foram utilizadas espiguetas de milho não polinizadas (estádio VT), trocadas a cada 48 horas. Nessa fase, a expressão das proteínas Bt é, possivelmente, superior àqueles valores encontrados por Balieiro Neto et al. (2013) para grãos na fase R3. Isso possivelmente explica a alta mortalidade de larvas encontradas no presente estudo.

Também foi observada interação significativa entre as espécies de Helicoverpa e híbridos de milho para o período de desenvolvimento pré-imaginal, e somente as larvas mantidas nos isogênicos completaram o período de desenvolvimento. Houve diferença apenas para o híbrido DKB390, no qual $H$. zea demorou aproximadamente 14 dias a mais para completar o ciclo, comparado ao de $H$. armigera. Esse resultado indica a possibilidade de um maior número de gerações $H$. armigera por ciclo de cultivo de milho. Assim, com um ciclo de cultivo de 150 dias, H. zea poderia completar 3,75 gerações, enquanto $H$. armigera, 5,88 gerações.

Sete dias após a eclosão, quando se aferiu o peso de larvas, houve efeito da interação entre espécie de Helicoverpa e os híbridos de milho, cuja diferença significativa foi apenas nos isogênicos não Bt $30 \mathrm{~F} 35$ e Impacto. Em estudos realizados na Austrália com algodão Cot102 (Syngenta) que expressa a proteína Vip3A, observou-se alto potencial no controle do

Tabela 2. Média \pm erro-padrão da sobrevivência pré-imaginal (SOBPI), do período de desenvolvimento pré-imaginal (PDPI), do peso larval e de pupas de Helicoverpa zea e Helicoverpa armigera nos diferentes híbridos de milho Bt e seus respectivos isogênicos convencionais ${ }^{(1)}$.

\begin{tabular}{|c|c|c|c|c|c|}
\hline \multirow[t]{2}{*}{ Milho } & \multirow{2}{*}{ Espécie } & \multicolumn{4}{|c|}{ Parâmetro biológico } \\
\hline & & SOBPI $(\%)^{(2)}$ & PDPI (dias) & Peso larval (mg) & Pupas (mg) \\
\hline \multirow{2}{*}{ 30F35HX (Cry1F) } & H. zea & $0,00 a(n=26)$ & - & $18,9 \pm 2,72 a(n=45)$ & - \\
\hline & H. armigera & $2,2 \pm 0,44 a(n=11)$ & - & $26,3 \pm 4,18 \mathrm{a}(\mathrm{n}=40)$ & - \\
\hline \multirow{2}{*}{ 30F35YG (Cry1A(b)) } & H. zea & $0,00 a(n=27)$ & - & $21,1 \pm 4,40 a(n=46)$ & - \\
\hline & H. armigera & $0,92 \pm 0,1 \mathrm{a}(\mathrm{n}=11)$ & - & - & - \\
\hline \multirow{2}{*}{$30 F 35$} & H. zea & $5,0 \pm 0,15 b(n=25)$ & $23,5 \pm 2,50 a(n=3)$ & $189,0 \pm 28,82 \mathrm{a}(\mathrm{n}=24)$ & $346,7 \pm 17,33 a(n=9)$ \\
\hline & H. armigera & $39,5 \pm 0,46 a(n=11)$ & $24,5 \pm 0,78 a(n=17)$ & $147,0 \pm 7,59 b(n=45)$ & $329,1 \pm 6,06 a(n=21)$ \\
\hline \multirow{2}{*}{ Impacto Viptera (Vip3A) } & H. zea & $0,0(n=25)$ & - & - & - \\
\hline & H. armigera & $0,0(n=11)$ & - & - & - \\
\hline \multirow{2}{*}{ Impacto } & H. zea & $7,6 \pm 0,15 b(n=25)$ & $25,5 \pm 0,72 \mathrm{a}(\mathrm{n}=6)$ & $241,7 \pm 47,09 a(n=15)$ & $290,6 \pm 29,69 a(n=3)$ \\
\hline & H. armigera & $39,6 \pm 0,12 \mathrm{a}(\mathrm{n}=11)$ & $24,3 \pm 0,33 a(n=11)$ & $115,6 \pm 7,03 b(n=44)$ & $334,5 \pm 7,96 a(n=30)$ \\
\hline \multirow{2}{*}{$\begin{array}{l}\text { DKB } 390 \text { VT PRO } \\
\text { (Cry1A.105+Cry2Ab2) }\end{array}$} & H. zea & $0,0(n=23)$ & - & $7,4 \pm 1,53 a(n=17)$ & - \\
\hline & H. armigera & $0,0(n=11)$ & - & - & - \\
\hline \multirow{2}{*}{ DKB 390} & H. zea & $1,4 \pm 0,21 b(n=35)$ & $39,5 \pm 11,50 a(n=2)$ & $100,1 \pm 9,94 a(n=60)$ & $399,9 \pm 9,97 a(n=6)$ \\
\hline & H. armigera & $19,8 \pm 0,30 a(n=11)$ & $25,4 \pm 0,62 b(n=11)$ & $105,0 \pm 7,61 \mathrm{a}(\mathrm{n}=45)$ & $341,1 \pm 14,03 b(n=21)$ \\
\hline Coeficiente de variação (\%) & & 56,05 & 13,33 & 11,95 & 12,70 \\
\hline
\end{tabular}

${ }^{(1)}$ Médias seguidas de letras iguais, na coluna, não diferem pelo teste de Scott Knott, a $5 \%$ de probabilidade. ${ }^{(2)}$ Dados transformados em $(\mathrm{x}+1)^{0,5}$. 
desenvolvimento das larvas de espécies do gênero de Helicoverpa sp. (Llewellyn et al., 2007), de acordo com os dados apresentados para milho, em que aos 7 dias houve $100 \%$ de mortalidade de ambas as espécies para essa proteína.

Os maiores valores de peso de larvas foram encontrados para H. zea no impacto Vip3A, seguido do híbrido $30 \mathrm{~F} 35$, que foram, respectivamente, cerca de 40 e $22 \%$ superiores aos pesos de $H$. armigera nos mesmos híbridos. Para as larvas submetidas à alimentação em milho Cry1F, o peso foi similar para ambas as espécies, assim como no isogênico DKB390 (Tabela 2).

Houve interação das espécies de Helicoverpa com os híbridos de milho para o peso das pupas. No entanto, somente para isogênicos convencionais houve número de larvas suficiente para a avaliação do peso (Tabela 2). O valor do peso de pupas nos isogênicos DKB390 foi diferente, sendo maior para $H$. zea do que para $H$. armigera. Babu et al. (2002) encontraram também efeito de inibição do crescimento de $H$. armigera em Cry2Aa e Cry1Ac. Essa redução do peso é uma típica atividade de proteína Bt exercida sobre noctuídeos-praga (Farias et al., 2014).

Verificou-se que H. zea apresentou valores absolutos do índice de adaptação (IA) aproximadamente 10 vezes inferiores àqueles observados para $H$. armigera (Tabela 3). Esse resultado mostra a maior adaptação de $H$. armigera por apresentar maior sobrevivência e menor período de desenvolvimento que $H$. zea. Assim, nota-se que $H$. armigera tem melhor condição de explorar o ambiente, o que pode ser comprovado pelo potencial de colonização dessa espécie em condições de campo nas diferentes regiões agrícolas, como observado no Brasil nas safras agrícolas 2012/2013 e 2013/2014 (Spech et al., 2013; Tay et al., 2013).

Tabela 3. Índice de adaptação de Helicoverpa zea e Helicoverpa armigera em diferentes híbridos de milho Bt e seus respectivos isogênicos convencionais.

\begin{tabular}{lcc}
\hline Híbrido de milho & Espécie & Índice de adaptação \\
\hline \multirow{2}{*}{$30 \mathrm{~F} 35$} & H. zea & 260,025 \\
& H. armigera & $1.185,255$ \\
\hline \multirow{2}{*}{ Impacto } & H. zea & 132,7907 \\
& H. armigera & $1.504,047$ \\
\hline \multirow{2}{*}{ DKB 390 } & H. zea & 146,63 \\
& H. armigera & $1.192,605$ \\
\hline
\end{tabular}

O hábito alimentar polífago, em associação com uma alta capacidade de dispersão e adaptação a diferentes cultivos, tende a favorecer o sucesso de $H$. armigera, como praga (Czepak et al., 2013).

Assim, observou-se efeito diferenciado das proteínas Bt expressas em milho para as duas espécies de Helicoverpa avaliadas no presente estudo, e a proteína Vip3A e a Cry1A.105 + Cry2Ab2 se mostraram mais promissoras para utilização em programas de manejo dessas espécies, com maior potencial de redução da população em campo. Além disso, $H$. armigera apresentou dados de maior adaptação que H. zea em híbridos de milho não Bt.

\section{Conclusões}

1. Há efeito da interação entre evento de milho Bt e espécie de Helicoverpa para as variáveis biológicas de sobrevivência larval, período letal e biomassa de larvas.

2. Larvas de Helicoverpa armigera apresentam maior sobrevivência 48 horas após eclosão em milho com expressão das proteínas Cry1F e Vip3 em relação a Helicoverpa zea, contudo, o período letal é maior em $H$. armigera do que em $H$. zea.

3. O período letal em milho que expressa a proteína Cry1A(b) é quatro vezes menor em $H$. armigera, e para Cry1F e Vip3A, o período letal é 3,5 vezes menor para H. zea.

4. Nos híbridos convencionais, Impacto e 30F35, $H$. armigera apresenta maior índice de adaptação que H. zea.

\section{Agradecimentos}

À Fundação de Amparo à Pesquisa do Estado de Minas Gerais (Fapemig), pelo aporte financeiro; e ao pesquisador da Embrapa Soja Daniel Ricardo Sosa-Gómez pela confirmação da espécie Helicoverpa armigera pela técnica Polimorfismo no Comprimento de Fragmentos de Restrição (RFLP).

\section{Referências}

ACOMPANHAMENTO DA SAFRA BRASILEIRA [DE] GRÃOS. Brasília: Conab, v.2, n.2, 2014. Safra 2014/15, segundo levantamento. Disponível em: <http://www.conab.gov.br/ OlalaCMS/uploads/arquivos/14_11_13_09_19_35_boletim graos_novembro_2014.pdf $>$. Acesso em: 23 nov. 2014. 
ÁVILA, C.J.; VIVAN, L.M.; TOMQUELSKI, G.V. Ocorrência, aspectos biológicos, danos e estratégias de manejo de Helicoverpa armigera (Hübner) (Lepidoptera: Noctuidae) nos sistemas de produção agrícolas. Dourados: Embrapa Agropecuária Oeste, 2013. 12p. (Embrapa Agropecuária Oeste. Circular técnica, 23). Disponível em: $<$ http://ainfo.cnptia.embrapa. br/digital/bitstream/item/96040/1/CT201323-REVAT-ONLINE. pdf >. Acesso em: 27 ago. 2013.

AVILLA, C.; VARGAS-OSUNA, E.; GONZÁLEZ-CABRERA, J.; FERRÉ, J.; GONZÁLEZ-ZAMORA, J.E. Toxicity of several $\delta$ endotoxins of Bacillus thuringiensis against Helicoverpa armigera (Lepidoptera: Noctuidae) from Spain. Journal of Invertebrate Pathology, v.90, p.51-54, 2005. DOI: 10.1016/j.jip.2005.04.003.

BABU, B.G.; UDAYASURIYAN, V.; MARIAM, M.A.; SIVAKUMAR, N.C.; BHARATHI, M.; BALASUBRAMANIAN, G. Comparative toxicity of Cry1Ac and Cry2Aa $\delta$-endotoxins of Bacillus thuringiensis against Helicoverpa armigera (H.). Crop Protection, v.21, p.817-822, 2002. DOI: 10.1016/S02612194(02)00044-3.

BALIEIRO NETO, G.; CIVIDANES, T.M. dos S.; BRANCO, R.B.; FELIX, M. do R.F.; REI, F.M. de C.T.; NOGUEIRA, J.R. Quantificação da proteína Cry1 Ab em folhas, caules e grãos de dois híbridos de milho Bt e controle das pragas Spodoptera frugiperda e Helicoverpa zea. Boletim de Indústria Animal, v.70, p.59-66, 2013. DOI: 10.17523/bia.v70n1p59.

BOIÇA JR., A.L.; MARTINELLI, S.; PEREIRA, M.F.A. Resistência de genótipos de milho ao ataque de Spodoptera frugiperda (JE Smith, 1797) e Helicoverpa zea (Boddie, 1850) (Lepidoptera: Noctuidae). Revista Ecossistema, v.26, p.86-90, 2001.

BOREGAS, K.G.B.; MENDES, S.M.; WAQUIL, J.M.; FERNANDES, G.W. Estádio de adaptação de Spodoptera frugiperda (J. E. Smith) (Lepidoptera: Noctuidae). Bragantia, v.72, p.61-70, 2013. DOI: 10.1590/S0006-87052013000100009.

BRAVO, A.; GILL, S.S.; SOBERÓN, M. Mode of action of Bacillus thuringiensis Cry and Cyt toxins and their potential for insect control. Toxicon, v.49, p.423-435, 2007. DOI: 10.1016/j. toxicon.2006.11.022.

CARNEIRO, A.A.; GUIMARÃES, C.T.; VALICENTE,F.H.; WAQUIL, J.M.; VASCONCELOS, M.J.V.; CARNEIRO, N.P.; MENDES, S.M. Milho Bt: teoria e prática da produção de plantas transgênicas resistentes a insetos-praga. Sete Lagoas: Embrapa Milho e Sorgo, 2009. 25p. (Embrapa Milho e Sorgo. Circular técnica, 135). Disponível em: <http://ainfo.cnptia.embrapa.br/ digital/bitstream/CNPMS-2010/22708/1/Circ-135.pdf>. Acesso em: 15 jun. 2013.

CRUZ, I. Controle biológico de pragas de milho. In: CRUZ, J.C.; KARAM, D.; MONTEIRO, M.A.R.; MAGALHÃES, P.C. (Ed.). A cultura do milho. Sete Lagoas: Embrapa Milho e Sorgo, 2008. p.363-415.

CUNNINGHAM, J.P.; ZALUCKI, M.P. Understanding heliothine (Lepidoptera: Heliothinae) pests: what is a host plant? Journal of Economic Entomology, v.107, p.881-896, 2014. Disponível em: $<$ http://www.ncbi.nlm.nih.gov/pubmed/25026644>. Acesso em: 24 mar. 2015.
CZEPAK, C.; ALBERNAZ, K.C.; VIVAN, L.M.; GUIMARÃES, H.O.; CARVALHAIS, T. Primeiro registro de ocorrência de Helicoverpa armigera (Hübner) (Lepidoptera: Noctuidae) no Brasil. Pesquisa Agropecuária Tropical,v.43, p.110-113, 2013. DOI: $10.1590 /$ S1983-40632013000100015.

FARIAS, J.R.; ANDOW, D.A.; HORIKOSHI, R.J.; SORGATTO, R.J.; FRESIA, P.; SANTOS, A.C. dos; OMOTO, C. Field-evolved resistance to Cry1F maize by Spodoptera frugiperda (Lepidoptera: Noctuidae) in Brazil. Crop Protection, v.64, p.150-158, 2014. DOI: 10.1016/j.cropro.2014.06.019.

FARIAS, J.R.; COSTA, E.C.; GUEDES, J.V.C.; ARBAGE, A.P.; NETO, A.B.; BIGOLIN, M.; PINTO, F.F. Managing the sugarcane borer, Diatraea saccharalis, and corn earworm, Helicoverpa $z e a$, using Bt corn and insecticide treatments. Journal of Insect Science, v.13, p.1-10, 2013. Art. 109.

GARCIA, M.S.; BUSATO, G.R.; ZART, M.; BERNARDI, O.; NUNES, A.M.; GIORGI, F.; BERNARDI, D. Volume de dieta artificial em recipientes de vidro para criação de Helicoverpa zea (Boddie, 1850) (Lepidoptera: Noctuidae). Revista Brasileira de Agrociência, v.12, p.363-366, 2006.

INFORMATIVO CÉLERES. Uberlândia: Céleres, IC 15.01, 20 jan. 2015. 13p.

LI, H.; BOUWER, G. Toxicity of Bacillus thuringiensis Cry proteins to Helicoverpa armigera (Lepidoptera: Noctuidae) in South Africa. Journal of Invertebrate Pathology, v.109, p.110116, 2012. DOI: 10.1016/j.jip.2011.10.005.

LLEWELLYN, D.J.; MARES, C.L.; FITT, G.P. Field performance and seasonal changes in the efficacy against Helicoverpa armigera (Hübner) of transgenic cotton expressing the insecticidal protein vip3A. Agricultural and Forest Entomology, v.9, p.93-101, 2007. DOI: 10.1111/j.1461-9563.2007.00332.x.

MENDES, S.M.; BOREGAS, K.G.B.; LOPES, M.E.; WAQUIL, M.S.; WAQUIL, J. M. Respostas da lagarta-do-cartucho a milho geneticamente modificado expressando a toxina Cry 1A (b). Pesquisa Agropecuária Brasileira, v.46, p.239-244, 2011.

MICHELOTTO, M.D.; FINOTO, E.L.; MARTINS, A.L.M.; DUARTE, A.P. Interação entre transgênicos (Bt) e inseticidas no controle de pragas chave em híbridos de milho safrinha. Arquivos do Instituto Biológico, v.78, p.71 79, 2011.

NASERI, B.; FATHIPOUR, Y.; MOHARRAMIPOUR, S.; HOSSEININAVEH, V.; GATEHOUSE, A.M.R. Digestive proteolytic and amylolytic activities of Helicoverpa armigera in response to feeding on different soybean cultivars. Pest Management Science, v.66, p.1316-1323, 2010. DOI: 10.1002/ ps.2017.

SPECHT, A.; SOSA-GÓMEZ, D.R.; PAULA-MORAES, S.V. de; YANO, S.A.C. Identificação morfológica e molecular de Helicoverpa armigera (Lepidoptera: Noctuidae) e ampliação de seu registro de ocorrência no Brasil. Pesquisa Agropecuária Brasileira, v.48. p.689-692, 2013. DOI: 10.1590/ S0100-204X2013000600015.

SRIVASTAVA, C.P.; JOSHI, N.; TRIVEDI, T.P. Forecasting of Helicoverpa armigera populations and impact of climate change. Indian Journal of Agricultural Sciences, v.80, p.3-10, 2010. 
TAY, W.T.; SORIA, M.F.; WALSH, T.; THOMAZONI, D.; SILVIE, P.; BEHERE, G.T.; ANDERSON, C.; DOWNES, S. A Brave New World for an Old World pest: Helicoverpa armigera (Lepidoptera: Noctuidae) in Brazil. PLoS One, v.8, p.1-7, 2013. DOI: 10.1371/ journal.pone.0080134.

UNITED STATES DEPARTMENT OF AGRICULTURE. World Agricultural Production. Washington, 2015. Available at: $<$ http:// www.fas.usda.gov/data/world-agricultural-production $>$. Accessed on: 10 Set. 2015.
WAQUIL, J.M.; DOURADO, P.M.; CARVALHO, R.A. de; OLIVEIRA, W.S.; BERGER, G.U.; HEAD, G.P.; MARTINELLI, S. Manejo de lepidópteros-praga na cultura do milho com o evento Bt piramidado Cry1A.105 e Cry2Ab2. Pesquisa Agropecuária Brasileira, v.48, p.1529-1537, 2013. DOI: 10.1590/ S0100-204X2013001200001.

WAQUIL, J.M.; VILLELA, F.M.F.; FOSTER, J.E. Resistência do milho (Zea mays L.) transgênico (Bt) à lagarta-do-cartucho, Spodoptera frugiperda (Smith) (Lepidoptera: Noctuidae). Revista Brasileira de Milho e Sorgo, v.1, p.1-11, 2002.

Recebido em 5 de janeiro de 2015 e aprovado em 14 de outubro de 2015 